\title{
Controle da qualidade do fruto de Syzygium cumini (L.) Skeels
}

\author{
Ketylin F. Migliato ${ }^{1,2}$, Raquel R.D. Moreira ${ }^{3}$, João C.P. Mello ${ }^{4,5}$, Luis V.S. Sacramento ${ }^{3}$, \\ Marcos A. Corrêa ${ }^{1}$, Hérida R.N. Salgado ${ }^{1,2 *}$
}

${ }^{1}$ Departamento de Fármacos e Medicamentos, Faculdade de Ciências Farmacêuticas, Universidade Estadual Paulista, 14801-902, Araraquara, SP, Brasil,

${ }^{2}$ Programa de Pós-Graduação em Ciências Farmacêuticas, Faculdade de Ciências Farmacêuticas, Universidade Estadual Paulista, 14801-902, Araraquara, SP, Brasil,

${ }^{3}$ Departamento de Princípios Ativos Naturais e Toxicologia, Faculdade de Ciências Farmacêuticas, Universidade Estadual Paulista, 14801-902, Araraquara, SP, Brasil,

${ }^{4}$ Departamento de Farmácia e Farmacologia, Universidade Estadual de Maringá, 87020-900, Maringá, PR, Brasil, ${ }^{5}$ Programa de Pós-Graduação em Ciências Farmacêuticas, Universidade Estadual de Maringá, 87020-900, Maringá, PR, Brasil

\begin{abstract}
RESUMO: Considerando-se a qualidade dos fitoterápicos, é importante salientar que a preocupação com esta questão inclui rigoroso acompanhamento das diferentes etapas do desenvolvimento e produção destes produtos, desde a coleta do vegetal até a disponibilidade do produto final. Neste trabalho foi realizado o controle da qualidade do fruto de Syzygium cumini (L.) Skeels, popularmente conhecido como jambolão. Para o controle físico-químico e microbiológico utilizaram-se metodologias farmacopéicas e não farmacopeicas. Os resultados obtidos mostraram que o fruto apresenta um teor de taninos de $4,2 \%$ e a análise fitoquímica preliminar dos frutos de $S$. cumini evidenciou taninos, flavonóides, antocianidinas, iridóides, alcalóides e heterosídeos fenólicos simples. A análise microbiológica não apresentou crescimento de patógenos entre os outros testes realizados. Destaca-se a importância do estabelecimento de normas para o controle da qualidade para as plantas, a fim de que sejam utilizadas com finalidade fitoterápica.
\end{abstract}

Unitermos: Syzygium cumini, Myrtaceae, controle da qualidade, fitoterápicos, controle da qualidade físico-químico, controle microbiológico.

\begin{abstract}
Quality control of Syzygium cumini (L.) Skeels fruits”. Considering the quality of the phytotherapic agents, it is important to point out that the concern with this subject includes rigorous attendance of the different steps of the development and production of these products, from the collection of the vegetable to the availability of the final product. In this work the quality control of the Syzygium cumini (L.) Skeels fruit, popularly known as jambolão, was carried out. Pharmacopoeic and no pharmacopoeic methodologies were employed to physico-chemical and microbiological quality control. The obtained results showed that the fruits presents a content of tannins of $4.2 \%$, the preliminary phytochemical analysis of the $S$. cumini fruits evidenced tannins, flavonoids, antocianidin, iridoids, alkaloids and heterosides simple phenols. The microbiological analysis didn't present phatogenic growth among the other accomplished tests. The work stands out the importance of the establishment of norms for the quality control for the plants, so that they are used with phytotherapic purpose.
\end{abstract}

Keywords: Syzygium cumini, Myrtaceae, quality control, phytotherapy, physico-chemical quality control, microbiologic control.

\section{INTRODUÇÃO}

As plantas representaram, durante séculos, a única fonte de agentes terapêuticos para o homem. No início do século XIX, com o desenvolvimento da química, as plantas passaram a representar a primeira fonte de substâncias para o desenvolvimento de medicamentos (Albuquerque; Hanazaki, 2006; Zaroni et al., 2004; Hostettmann et al., 2003).

Muitas empresas estão conscientes das tendências de consumo, e buscam novos ingredientes para incorporar aos produtos já existentes e aos que poderão ser desenvolvidos no futuro. Uma tendência que está se destacando é o aumento na procura por parte da população, de produtos funcionais baseados em ativos ou fitoterápicos (Rocha Filho, 1995; Oliveira; Bloise, 1995).

Observando a necessidade do mercado e a falta de especificação, o presente trabalho estudou a planta Syzygium cumini (L.) Skeels (sinonímia: Eugenia jambolana Lam.), uma árvore nativa dos trópicos, particularmente da Índia, bem como da Tailândia, 
Filipinas e Madagascar. A planta foi introduzida em muitos países tropicais pertencentes à África e à América Latina. No Brasil é encontrada em diversos estados das regiões Sudeste, Nordeste e Norte. Pode também ser encontrada em algumas regiões subtropicais como a Flórida e a Califórnia nos Estados Unidos, a Argélia e Israel (Migliato et al., 2006; Alberton et al., 2001; Mahmoud et al., 2001; Grover et al., 2001).

Syzygium cumini, popular jambolão, se destaca por ser rico em vários constituintes. A literatura relata suas ações hipoglicemiante, antimicrobiana, hipotensiva, diurética, cardiotônica, adstringente, antiinflamatória, antiemética, estimulante do sistema nervoso central, antipirética, anticonvulsivante, anti-hemorrágica, carminativa e antiescorbútica. Tal situação tem popularizado seu emprego no tratamento de constipação, leucorréia, úlcera venérea, purificação de sangue, interrupção de hemorragia nas fezes, disenteria, dispepsia, asma, bronquite, gengivite, estomatite, queimaduras, retenção urinária e descamações do couro cabeludo (Michelin et al., 2005; Barbosa-Filho et al., 2005; Pereira et al., 2004; Sharma et al., 2003; Zanoello et al., 2002; Damasceno et al., 2002; Timbola et al., 2002; Pepato et al., 2001; Santos et al., 1995).

A composição química das sementes, cascas, folhas, frutos e flores do jambolão tem sido referenciada por diversos autores (Sharma et al., 2003; Zanoello et al., 2002; Damasceno et al., 2002; Ahmad; Beg, 2001; Mahmoud et al., 2001; Nascimento et al., 2000). Nas sementes foram encontrados taninos hidrolisáveis (ácido gálico, elágico, corilágico), quercetina, antimelina, óleo essencial ( $\alpha$ - e $\beta$-pineno, canfeno, mirceno, limoneno, cis-ocimeno, trans-ocimeno, $\gamma$-terpineno, acetato de bornila, $\alpha$-copaeno, $\alpha$-humuleno e candineno), materiais resinosos e glicose; nas cascas foram encontrados ácido acetil oleanólico, triterpenóides, ácido elágico, isoquercetina, quercetina, canferol e miricetina; nas folhas foram encontrados ácido gálico, metilgalato, canferol, miricetina, ácido elágico, ácido clorogênico, quercetina e nilocitina; nos frutos foram encontradas antocianidinas e nas flores, o ácido oleanólico (Migliato et al., 2006; Sharma et al., 2003; Damasceno et al., 2002; Timbola et al., 2002; Alberton et al., 2001; Mahmoud et al., 2001).

$\mathrm{O}$ presente trabalho teve por objetivo $\mathrm{o}$ desenvolvimento do controle da qualidade do fruto de Syzygium cumini (L.) Skeels.

\section{MATERIAL E MÉTODOS}

\section{Material vegetal}

Os frutos maduros de Syzygium cumini (L.) Skeels foram coletados nos meses de dezembro de 2003 a janeiro de 2004, no Horto de Plantas Medicinais e Tóxicas da FCF/UNESP, em Araraquara - SP. Na mesma ocasião, foram amostrados ramos da mesma árvore para o processo de conferência de exsicata que está depositada sob o número SJRP 19586 no Herbário do Departamento de Botânica do IBILCE-UNESP, Campus de São José do Rio Preto (SP).

\section{Preparo, secagem e moagem do material}

Os frutos frescos maduros colhidos foram submetidos à secagem em estufa com ar circulante, à temperatura de $45^{\circ} \mathrm{C}$, até a estabilização do peso. Após esta condição executou-se a moagem em moinho de facas seguida pelo emprego de moinho de bolas. Este processo duplo objetivou reduzir o tamanho das partículas de modo a aumentar, posteriormente, seu contato com o líquido extrator.

\section{Análise granulométrica}

Baseado na Farmacopéia Brasileira (1988) e com o objetivo de padronizar a granulometria, 25 $\mathrm{g}$ do pó do fruto moído foram submetidos à passagem forçada por vibração, através de tamises com abertura de malhas e coletor correspondentes a 0,$125 ; 0,177$; 0,$420 ; 0,840 ; 2,00 \mathrm{~mm}$, utilizando tamisador vibratório, na escala dez do aparelho, durante trinta minutos. Após este processo, as frações foram retiradas dos tamises e do coletor e quantificadas quanto às suas proporções. Este procedimento foi realizado em triplicata. Para os estudos de passagem e retenção a partir da quantidade de pó do fruto recolhida de cada tamis, foram elaboradas planilhas no software Excel $^{\circledR}$ onde foram calculadas as freqüências percentuais e também as freqüências percentuais cumulativas.

\section{Determinação da densidade bruta do pó do fruto}

Para determinar a densidade bruta do pó do fruto, foram amostrados $50 \mathrm{~g}$, os quais foram distribuídos em encapsulador contendo 25 cápsulas de tamanho 00. Em seguida, o peso foi determinado e a densidade calculada pela relação massa/volume do pó. Este procedimento foi repetido três vezes com três amostras distintas (Martins; Sacramento, 2004).

\section{Perda por secagem do fruto fresco}

Cerca de 10,0 g, exatamente pesados, da droga vegetal fresca foram colocados para secagem em temperatura ambiente, com ausência de luminosidade. Foram pesados diariamente até peso constante. Os resultados foram expressos em perda de substâncias voláteis e/ou água percentual, pela média de cinco determinações (Mello; Petrovick, 2000).

\section{Determinação da perda por dessecação em balança com infravermelho do pó do fruto}

Amostras de 4,0 g do pó do fruto, exatamente

\begin{tabular}{r|c} 
Rev. Bras. Farmacogn. & 95 \\
Braz J. Pharmacogn. & \\
17(1). Jan./Mar. 2007 &
\end{tabular}


pesadas, foram submetidas ao aquecimento $\left(110^{\circ} \mathrm{C}\right)$ por raios infravermelhos pelo período de aproximadamente 1 hora. Após este período foi feita a determinação do peso. Este procedimento foi realizado de hora em hora até que o peso não variasse mais do que $0,25 \%$. Os valores foram expressos em porcentagem $(\mathrm{p} / \mathrm{p})$, pela média de três determinações (Mello; Petrovick, 2000).

\section{Determinação do pH}

De acordo com a Farmacopéia Brasileira (2000), uma solução a $1 \%$ (p/v) do pó do fruto em água destilada foi aquecida até ebulição em chapa-elétrica por 5 min. Após este tempo foi realizada uma filtração em funil contendo algodão como elemento filtrante. Após o resfriamento mediu-se o $\mathrm{pH}$ do filtrado utilizando potenciômetro previamente calibrado. Os resultados foram expressos pela média de três determinações.

\section{Determinação do teor de cinzas}

Foi calcinado previamente o cadinho de porcelana em mufla à $450{ }^{\circ} \mathrm{C}$ por $30 \mathrm{~min}$. $\mathrm{O}$ mesmo foi resfriado em dessecador (15 $\mathrm{min})$ e seu peso foi determinado em balança analítica. Foram pesados exatamente $3,0 \mathrm{~g}$ do pó do fruto, os quais foram distribuídos de maneira uniforme e submetidos à calcinação em mufla à temperatura de $450{ }^{\circ} \mathrm{C}$ por duas horas. A amostra foi deixada em dessecador para arrefecimento durante 30 min e pesagem posterior. Foi repetida a técnica até peso constante. Os resultados foram expressos em porcentagem em peso de cinzas na droga seca $(\%, \mathrm{p} / \mathrm{p})$ e representando a média de três determinações (Farmacopéia Brasileira, 2000).

\section{Determinação do teor de extrativos}

Segundo Mello e Petrovick (2000), cerca de $1,0 \mathrm{~g}$ do pó do fruto, exatamente pesado, foi submetido à decocção com 100,0 mL de água, durante $10 \mathrm{~min}$. Após resfriamento, o volume foi completado a 100,0 $\mathrm{mL}$. A solução obtida foi filtrada em papel de filtro e os primeiros 20,0 $\mathrm{mL}$ foram desprezados. Do restante do filtrado, pesou-se uma alíquota equivalente a 20,0 g, em pesa-filtro previamente tarado e evaporou-se até secura em banho de água, sob agitação constante. $\mathrm{O}$ resíduo foi colocado em estufa, à temperatura de $105{ }^{\circ} \mathrm{C}$ por $3 \mathrm{~h}$. Em seguida, resfriado em dessecador e pesado. $\mathrm{O}$ teor de extrativos foi calculado em massa percentual, pela média de três determinações segundo a equação:

$$
T E=\frac{g * F D * 100}{M}
$$

Onde: $\mathrm{TE}=$ teor de extrativos $(\% ; \mathrm{m} / \mathrm{m}), \mathrm{g}=$ massa de resíduo seco $(\mathrm{g}), \mathrm{M}=$ massa da $\operatorname{amostra}(\mathrm{g}), \mathrm{FD}=$ fator de diluição (5)

\section{Análise fitoquímica preliminar}

Essas análises objetivaram estabelecer o conhecimento de grupos químicos por reações químicas segundo Harborne (1998): 1) cumarinas; 2) heterosídeos fenólicos simples; 3) saponinas; 4) antracênicos; 5) taninos; 6) alcalóides; 7) iridóides; 8) goma resina; 9) flavonóides; 10) anel esteroidal/ triterpênicos; 11) metilxantinas; 12) antocianidinas.

\section{Determinação do teor de taninos totais}

A metodologia utilizada foi baseada no trabalho de Glasl (1983), na qual uma amostra de $0,750 \mathrm{~g}$ do pó do fruto, exatamente pesada, foi transferida para erlenmeyer com 150,0 $\mathrm{mL}$ de água, e deixada durante $30 \mathrm{~min}$ em banho termostatizado à temperatura de $80-90^{\circ} \mathrm{C}$. Após este período, o erlenmeyer foi resfriado em água corrente e o seu conteúdo transferido quantitativamente para balão volumétrico de $250,0 \mathrm{~mL}$, aferindo-se o volume. Após a homogeneização todo o conteúdo foi filtrado desprezando-se os primeiros $50,0 \mathrm{~mL}$, e o filtrado restante foi acondicionado em frasco âmbar sendo denominado de solução-mãe (SM).

Para a determinação de polifenóis totais (PT), 5,0 $\mathrm{mL}$ da SM foram diluídos com água em balão volumétrico de $25,0 \mathrm{~mL}$. Dois mililitros desta solução foram transferidos e adicionados de $1,0 \mathrm{~mL}$ de solução de ácido fosfotúngstico R (Reagente fenólico de Folin-Ciocalteu 2 $\mathrm{N})$ e 10,0 mL de água para balão volumétrico de $25,0 \mathrm{~mL}$, sendo completado o volume com solução de carbonato de sódio a 14,06\% 15 min após a adição da última solução foi medida a absorvância a $691 \mathrm{~nm}$, sendo empregada a água como branco. Para determinação de polifenóis não adsorventes (PNA), 10,0 mL de SM foram transferidos e adicionados de $0,100 \mathrm{~g}$ de pó-de-pele $\mathrm{R}$ para béquer e agitados durante $60 \mathrm{~min}$. Após, a solução foi filtrada. Cinco mililitros do filtrado foram diluídos com água para $25,0 \mathrm{~mL}$ em balão volumétrico. Dois mililitros do filtrado desta solução foram transferidos e adicionados de 1,0 mL de solução de ácido fosfotúngstico $\mathrm{R}$ (Reagente fenólico de Folin-Ciocalteu $2 \mathrm{~N}$ ) e $10,0 \mathrm{~mL}$ de água para balão volumétrico de $25,0 \mathrm{~mL}$ sendo completado o volume com solução de carbonato de sódio a 14,06\%. Após a adição da última solução foi esperado 15 min e foi medida a absorvância a $691 \mathrm{~nm}$, sendo empregada a água como branco. O conjunto de operações (extrações e diluições) foi realizado sob proteção da ação da luz direta.

A porcentagem de taninos totais foi calculada segundo as fórmulas:

$$
\begin{gathered}
P T=\frac{15625 * A b s}{1000 * m} \quad P N A=\frac{15625 * A b s}{1000 * m} \\
T T=P T-P N A
\end{gathered}
$$

Onde: $\mathrm{PT}=$ Polifenóis totais $(\%), \mathrm{PNA}=$ Polifenóis não 
adsorventes (\%), Abs.= Absorvância medida, $\mathrm{m}=$ massa da droga em $\mathrm{g}, \mathrm{TT}=$ teor de taninos totais $(\%)$

\section{Contagem total de microrganismos}

Foram transferidos, assepticamente, 10,0 g do pó do fruto para $90,0 \mathrm{~mL}$ de solução tampão fosfato pH 7,2, para a contagem dos microrganismos totais. A amostra 1:10 foi submetida à agitação durante $10 \mathrm{~min}$. Após a homogeneização, foi pipetado $1,0 \mathrm{~mL}$ da amostra 1:10 e adicionados 20,0 $\mathrm{mL}$ de ágar tioglicolato para bactérias e ágar Sabouraud para leveduras, a $47{ }^{\circ} \mathrm{C} \mathrm{em}$ placa de Petri, que foram colocadas em estufa a $35{ }^{\circ} \mathrm{C}$ por $24 \mathrm{~h}$ e $25^{\circ} \mathrm{C}$ por 7 dias, para a pesquisa de bactérias e fungos, respectivamente. Após este período, foi realizada a contagem do número de colônias com o auxílio de contador de colônias, calculando o número de unidades formadoras de colônias (UFC/mL) (USP, 2003; Pinto et al., 2003).

\section{Pesquisa de Salmonella sp e Escherichia coli}

Foram transferidos, assepticamente, 10,0 g do pó do fruto para $90,0 \mathrm{~mL}$ de caldo lactosado, para pesquisa de Salmonella sp e E. coli, incubados a $35^{\circ} \mathrm{C}$ durante 24 a $48 \mathrm{~h}$. Após este período, $1 \mathrm{~mL}$ do caldo lactosado foi transferido para 2 tubos contendo caldo tetrationato e caldo selenito cistina, que foram incubados a $35{ }^{\circ} \mathrm{C}$ por $24 \mathrm{~h}$. Após este período, a amostra foi semeada do caldo tetrationato para 1 tubo contendo ágar verde brilhante e duas placas de Petri contendo ágar xiloselisina-desoxicolato (XLD) e ágar bismuto sulfito. Foi realizado da mesma forma com a amostra inoculada no caldo selenito cistina, transferindo para os três meios, os quais foram incubados a $35{ }^{\circ} \mathrm{C}$ por $24 \mathrm{~h}$. O crescimento e as características das colônias foram observados. As colônias suspeitas foram semeadas com alça reta em tubo contendo ágar tríplice açúcar-ferro (TSI) e incubado a 35 ${ }^{\circ} \mathrm{C}$ por 24 h. A confirmação da Salmonella foi feita pelo método de Gram.

Na pesquisa de E. coli, 1,0 mL do caldo lactosado foi transferido para placa contendo ágar Mac Conkey e incubado a $35^{\circ} \mathrm{C}$ por $24 \mathrm{~h}$. As colônias suspeitas foram semeadas em ágar eosina-azul de metileno (EMB) e incubadas a $35^{\circ} \mathrm{C}$ por $24 \mathrm{~h}$. A confirmação da $E$. coli foi realizada através de método de Gram (USP, 2003; Pinto et al., 2003).

\section{Pesquisa de Staphylococcus aureus e Pseudomonas aeruginosa}

Foram transferidos, assepticamente, 10,0 g do pó do fruto para $90,0 \mathrm{~mL}$ de caldo soja-caseína, para a pesquisa de $S$. aureus e $P$. aeruginosa e incubados a $35{ }^{\circ} \mathrm{C}$ por 24 a $48 \mathrm{~h}$. Após este período, uma alçada foi semeada em placas de ágar Vogel Johnson e ágar cetrimida, para a pesquisa de $S$. aureus e $P$. aeruginosa, respectivamente as placas foram incubadas a $35{ }^{\circ} \mathrm{C}$ por $24 \mathrm{~h}$. As características das colônias foram observadas e a confirmação foi realizada através de método de coloração de Gram (USP, 2003; Pinto et al., 2003).

\section{RESULTADOS}

A avaliação granulométrica do material moído é um parâmetro importante a ser estabelecido, pois representa uma influência direta sobre a eficiência no processo extrativo. Os resultados da avaliação da granulometria estão apresentados na Tabela 1.

A aplicação de análise estatística dos resultados expressos na Tabela 1 e demonstrada na Figura 1 permitiu detectar um diâmetro médio de partículas de 0,302 mm.

Vários ensaios foram realizados com o objetivo de controlar a qualidade do material botânico. As análises físico-químicas envolveram a perda por secagem (utilizando-se do material fresco), a determinação da perda por dessecação, determinação do pH, determinação do teor de cinzas e determinação do teor de extrativos. Com relação à análise química, realizou-se análise fitoquímica preliminar e posteriormente análise química quantitativa para a determinação do teor de taninos totais (Tabela 2).

Os dados das análises fitoquímicas preliminares, realizadas com os frutos de jambolão, referidos na Tabela 3, mostram grupos de substâncias químicas que podem ser empregadas para a caracterização da matéria-prima. É o caso dos taninos, flavonóides, alcalóides, heterosídeos

Tabela 1. Análise granulométrica do pó dos frutos de S. cumini.

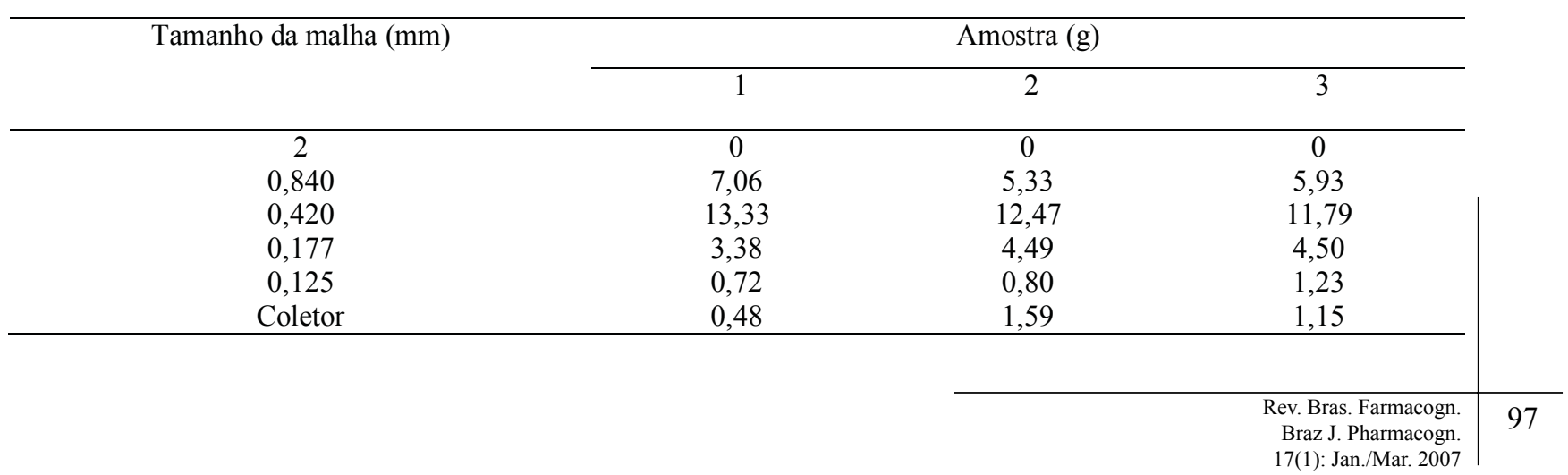




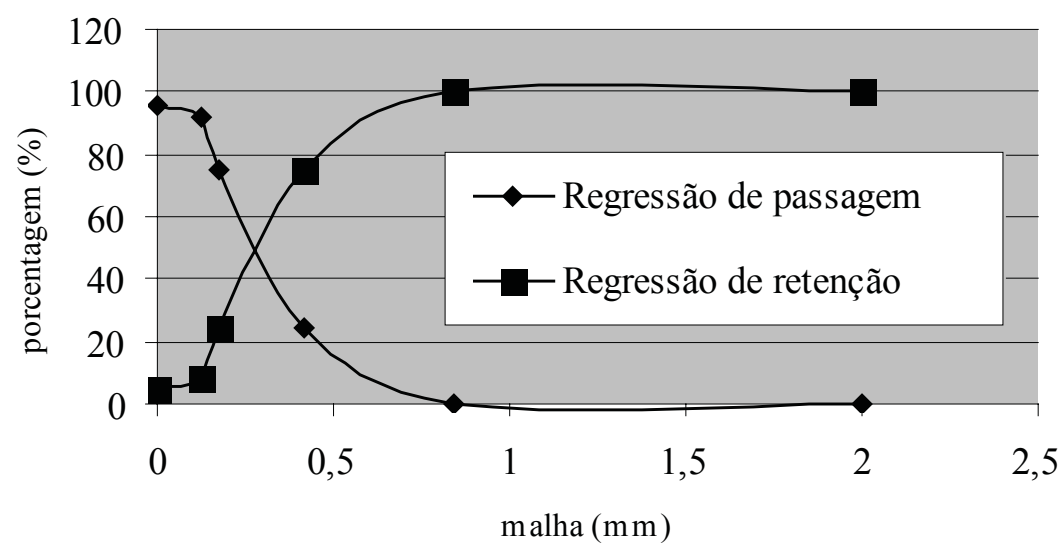

Figura 1. Tamanho da partícula média do pó dos frutos de S. cumini. Média de três observações.

fenólicos simples, iridóides e antocianidinas.

Os resultados obtidos através do controle microbiológico do pó do fruto de jambolão (Tabela 4) permitiram observar que não houve crescimento microbiano de Salmonella sp, Escherichia coli, Staphylococcus aureus e Pseudomonas aeruginosa, considerados microrganismos patogênicos nas amostras analisadas, porém ocorreu crescimento de fungos dentro do limite permitido para drogas vegetais. $\mathrm{Na}$ contagem do número total de bactérias do pó do fruto, houve crescimento inferior a $10 \mathrm{UFC} / \mathrm{g}$ e para fungos ocorreu o crescimento de $40 \mathrm{UFC} / \mathrm{g}$.

\section{DISCUSSÃO}

Seguindo as exigências da resolução ANVISA RDC no 48/2004, e a ausência de estudos de controle da qualidade, foi traçado o perfil da droga vegetal Syzygium cumini (L.) Skeels, em consonância com as exigências legislativas, e de tal forma, que pudesse colaborar com preceitos da qualidade para a droga vegetal proposta (ANVISA, 2004).

Considerando que o presente trabalho propôs-se a buscar e comprovar o controle da qualidade do fruto e do extrato de frutos do jambolão e considerando ainda, a já bem documentada atividade antimicrobiana apresentada pelos taninos, justifica-se a realização do doseamento deste grupo de substâncias presentes no pó do fruto de $S$. cumini (Tabela 2).

A determinação da perda por secagem constituiuse num ensaio difícil de ser realizado, pois os frutos de jambolão por apresentarem polpa carnosa e, quando maduros, grandes quantidades de açúcares, apresentaram o desenvolvimento de fungos durante a determinação. As mesmas dificuldades foram enfrentadas por Alberton et al. (2001) quando observaram que a secagem do material à temperatura ambiente pode trazer prejuízos à qualidade final da droga vegetal considerada. No presente trabalho ocorreu a perda de $86,5 \%$ de água, apesar do desenvolvimento de fungos. Em função das dificuldades encontradas, entende-se não ser recomendável a realização deste tipo de análise como metodologia para secagem do fruto em grande quantidade, por isso foi utilizada a secagem em estufa de ar circulante por sete dias, a qual impede o desenvolvimento de microrganismos e também diminui o tempo de secagem, pois ao realizar-se a perda por secagem houve demora de trinta dias para que ocorresse a estabilização.

A determinação da perda por dessecação do pó do fruto de $S$. cumini foi realizada em balança de infravermelho à temperatura de $110^{\circ} \mathrm{C}$ por um período de uma hora apresentando uma perda de $6,01 \%$, quando ocorreu estabilização do processo.

Este tipo de análise é importante uma vez que pode oferecer informações importantes com referência ao armazenamento da droga vegetal. A água residual encontrada na droga vegetal seca está diretamente relacionada com o seu correto armazenamento, que pode acarretar na perda do material por contaminação microbiana ou degradação dos constituintes químicos. Pode-se afirmar que os valores característicos da perda por dessecação, além de informação importante do ponto de vista tecnológico, servem também como parâmetro de controle da qualidade do pó do fruto de S. cumini.

$\mathrm{O}$ valor de $\mathrm{pH}$ do extrato da droga vegetal foi 4,09 utilizando água com $\mathrm{pH}$ de 6,25 , o que sugere a presença de substâncias ácidas no farmacógeno estudado.

Quanto à determinação do teor de cinzas, utilizou-se o hamamelis (Hamamelis virginiana L.) (cascas), como um parâmetro comparativo. Os teores encontrados foram: 9,56\% para o jambolão e 9,14\% para a hamamelis. Em se tratando de drogas vegetais, o principal objetivo deste tipo de ensaio é a verificação de impurezas inorgânicas não-voláteis que podem estar presentes como contaminantes (Farmacopéia Brasileira, 2000). 
Tabela 2. Análise física, físico-química, química e microbiológica.

\begin{tabular}{ll}
\hline Parâmetros & Valores obtidos \\
\hline Diâmetro médio das partículas & $0,302 \mathrm{~mm}$ \\
Densidade bruta & $0,86 \mathrm{~g} / \mathrm{mL}$ \\
Perda por secagem & $86,5 \%$ \\
Perda por dessecação & $6,01 \%$ \\
$\mathrm{pH}$ & 4,09 \\
Teor de cinzas & $9,56 \%$ \\
Teor de extrativos & $2,37 \%$ \\
Fitoquímica preliminar & Heterosídeos fenólicos simples, taninos, alcalóides, iridóides, flavonóides, \\
& antocianidinas \\
Teor de taninos & $4,2 \%$ \\
Análise microbiológica & Ausência de microrganismos patogênicos e presença inferior ao aceito para \\
& fungos \\
\hline
\end{tabular}

Tabela 3. Análise fitoquímica preliminar do pó dos frutos de S. cumini.

\begin{tabular}{lc}
\hline Substância ativa & Resultado \\
\hline Cumarinas & - \\
Heterosídeos fenólicos simples & + \\
Saponinas & - \\
Antracênicos & - \\
Taninos & + \\
Alcalóides & + \\
Iridóides & + \\
Goma resina & - \\
Flavonóides & + \\
Anel esteroidal/ triterpênicos & + \\
Metil-xantinas & - \\
Antocianidinas & - \\
\hline
\end{tabular}

+ presença do grupo químico; - ausência do grupo químico

Tabela 4. Análise microbiológica do pó dos frutos de $S$. cumini.

\begin{tabular}{lcc}
\hline Microrganisnos & Recomendação ${ }^{*}$ & Resultado \\
\hline Microrganismos aeróbios viáveis & $\leq 10^{5} \mathrm{UFC} / \mathrm{g}$ & Inferior $10 \mathrm{UFC} / \mathrm{g}$ \\
Fungos & $\leq 10^{4} \mathrm{UFC} / \mathrm{g}$ & $40 \mathrm{UFC} / \mathrm{g}$ \\
Enterobactérias/ Bactérias Gram-negativas & $\leq 10^{3} \mathrm{UFC} / \mathrm{g}$ & Ausente \\
Escherichia coli & Ausência & Ausente \\
Salmonella sp. & Ausência & Ausente \\
Staphylococcus aureus & Ausência & Ausente \\
Pseudomonas aeruginosa & Ausência & Ausente \\
\hline
\end{tabular}

* Fonte: Pinto et al., 2003; USP 2003.

Com o objetivo de avaliar-se a quantidade de substâncias extraíveis, denominado de teor de extrativos, e de acordo com a Organização Mundial da Saúde (WHO, 1998), empregou-se a decocção em água. O rendimento encontrado foi de $2,37 \%$. No entanto, é importante levar em consideração a substância que se deseja extrair. Por exemplo, para taninos, foi demonstrado ser necessário o emprego de misturas de solventes como o metanol: água ou acetona: água. Refere-se, inclusive, que a extração com o sistema acetona:água, apesar de significativamente maior, representa um sistema com menor estabilidade para os taninos. Quando se considera a extração cujo solvente é somente a água, a estabilidade do extrato torna-se ainda mais comprometida, uma vez que o risco de contaminação microbiológica aumenta significativamente.

Plantas medicinais produzem diferentes substâncias químicas (alcalóides, taninos, flavonóides, saponinas, entre outros) e o fazem em diferentes proporções, dependendo do habitat, do regime de chuvas, da insolação, do solo, enfim, das características climáticas- 
edáficas. Entretanto, algumas substâncias químicas são bastantes características para um determinado vegetal, e desta forma podem servir como parâmetro para sua caracterização e identificação.

O doseamento realizado para a avaliação do teor de taninos totais presentes nos frutos de jambolão, detectou a presença de 4,2\% desta substância. Tal valor pode ser considerado baixo quando comparado com o teor de taninos encontrado no Stryphnodendron adstringens (Mart.) Coville, conhecido popularmente como barbatimão, cujo teor mínimo é de $20 \%$, porém, o valor encontrado pode ser considerado razoável, quando comparado, por exemplo, com a Krameria triandra Ruiz e Pavon., conhecida como ratânia, cujo teor é de aproximadamente $10 \%$. Apesar de apresentar valores não muito elevados em taninos, a possibilidade de se encontrar efeito antimicrobiano não pode ser descartada, pois este efeito pode ser resultado da contribuição de outros grupos químicos presentes.

Considerando os diversos aspectos impostos para a garantia da qualidade do material botânico, que englobam não somente os aspectos físico-químicos, mas também o microbiológico, e considerando-se ainda, o fato dos materiais vegetais conterem um grande número de fungos e bactérias (pertencentes à sua microbiota natural ou mesmo introduzidas durante a manipulação, contaminação esta que pode ser intensificada com o tempo e não somente comprometer o material em si, mas também o usuário), procurou-se realizar um controle microbiológico do pó do fruto de $S$. cumini.

Ao realizar o controle microbiológico o resultado encontrado torna-se interessante, uma vez que não foi encontrado nenhum tipo de microrganismo patogênico, o que pode ser resultado das boas práticas na coleta e manipulação. Outro fato que pode estar associado a esta característica é a presença de taninos condensados, os quais vêm sendo pesquisados por suas propriedades farmacológicas e fisiológicas. Devido à propriedade de se combinarem com as proteínas das plantas, os taninos protegem-nas contra o ataque de herbívoros, microrganismos, além de apresentarem inibição enzimática em humanos (Galloway, 1989).

\section{CONCLUSÃO}

As metodologias empregadas foram adequadas para avaliar a qualidade da droga vegetal (pó do fruto), embora a perda por dessecação do fruto fresco tenha apresentado alguns entraves. Todas as etapas cumpridas no presente trabalho são importantes e devem ser recomendas como parâmetros seguros para o controle de qualidade do pó fruto de $S$. cumini.

\section{AGRADECIMENTOS}

Ao CNPq-Brasília, ao PADC-FCF-UNESP, FUNDUNESP e a CAPES. À Maria de Fátima Rodrigues
Lopes, Eduardo Santos, Admir Arantes pelo apoio técnico.

\section{REFERÊNCIAS}

Ahmad I, Beg AZ 2001. Antimicrobial and phytochemical studies on 45 Indian medicinal plants against multidrug resistant human pathogens. $J$ Ethnopharmacol 74: 113-123.

Alberton JR, Ribeiro A, Sacramento LVS, Franco SL 2001. Caracterização farmacognóstica do jambolão (Syzygium cumini (L.) Skeels). Rev Bras Farmacogn 11: $37-50$.

Albuquerque UP, Hanazaki N 2006. As pesquisas etnodirigidas na descoberta de novos fármacos de interesse médico e farmacêutico: fragilidades e pespectivas. Rev Bras Farmacogn 16(Supl.): 678-689.

ANVISA 2004. Agência Nacional de Vigilância Sanitária, Brasil, Leis, decretos, etc. Resolução no 48 , de 16 de março de 2004. Dispõe sobre o registro de medicamentos fitoterápicos. Diário Oficial da República Federativa do Brasil, Brasília.

Barbosa-Filho JM, Vasconcelos THC, Alencar AA, Batista LM, Oliveira RAG, Guedes DN, Falcão HS, Moura MD, Diniz MFFM, Modesto-Filho J 2005. Plants and their active constituents from South, Central, and North America with hypoglycemic activity. Rev Bras Farmacogn 15: 392-413.

Damasceno DC, Lima PHO, Galhiane MS, Volpato GT, Rudge MVC 2002. Avaliação do efeito hipoglicemiante da sapogenina extraída de sementes de Eugenia jambolana Lam. Rev Bras Plantas Med 4: 46-54.

Farmacopéia Brasileira 1988. 4 ed. São Paulo: Atheneu.

Farmacopéia Brasileira 2000. 4 ed. São Paulo: Atheneu.

Galloway DF 1989. The biological significance of tannins: an overview. In: Hemingway RW, Karchesy J J Chemistry and significance of condensed tannins. New York: Plenum Press, p. 447.

Glasl H 1983. Zur photometrie in der drogenstandardisierung3. Gehaltsbestimmung von Gerbstoffdrogen. Deutsche Apotheker Zeitung 123: 1979-1987.

Grover JK, Vats V, Rathi SS, Dawar R 2001. Traditional Indian anti-diabetic plants attenuate progression of renal damage in streptozotocin induced diabetic mice. $J$ Ethnopharmacol 76: 233-238.

Harborne JB 1998. Phytochemical methods: a guide to modern techniques of plant analysis. 2. ed. London: Chapman and Hill, $288 \mathrm{p}$.

Hostettmann K, Queiroz EF, Vieira PC 2003. Principios ativos de plantas superiores. São Carlos: EdUFSCar, p. 09, 60-61.

Mahmoud II, Marzouk MAS, Maharram FA, El-Gindi MR, Hassan AMK 2001. Acylated flavonol glycosides from Eugenia jambolana leaves. Phytochemistry 58: 1239-1244.

Martins AB, Sacramento LVS 2004. Análise microscópica e física para controle de qualidade primária de matériaprima vegetal pulverizada. $16^{\circ}$ Congresso de Iniciação Cientifica UNESP. Ilha Solteira, Brasil.

Mello JCP, Petrovick PR 2000. Quality control of Baccharis trimera (Less) DC (Asteraceae) hydroalcoholic extracts. Acta Farm Bonaerense 19: 211-215. 
Michelin DC, Moreschi PE, Lima AC, Nascimento GGF, Paganelli MO, Chaud MV 2005. Avaliação da atividade antimicrobiana de extratos vegetais. Rev Bras Farmacogn 15: 316-320.

Migliato KF, Baby AR, Zague V, Velasco MVR, Corrêa MA, Sacramento LVS, Salgado HRN 2006. Ação farmacológica de Syzygium cumini (L.) Skeels. Acta Farm Bonaerense 25: 310-304.

Nascimento GGF, Locatelli J, Freitas PC, Silva GL 2000. Antibacterial activity of plant and phytochemicals on antibiotic- resistant bacteria. Braz J Microbiol 31: 247-256.

Oliveira LC, Bloise MI 1995. Extratos e óleos naturais vegetais funcionais. Cosmetics \& Toiletries 7: 30-37.

Pepato MT, Folgado VBB, Kettelhut IC, Brunetti IL 2001. Lack of antidiabetic effect of Eugenia jambolana leaf decoction on rat streptozotocin diabetes. Braz J Med Biol Res 34: 389-395.

Pereira RC, Oliveira MTR, Lemos GCS 2004. Plantas utilizadas como medicinais no município de Campos de Goytacazes - RJ. Rev Bras Farmacogn 14 (Supl. 1): $37-40$.

Pinto TJA, Kaneko TM, Ohara MT 2003. Controle biológico de qualidade de produtos farmacêuticos, correlatos e cosméticos. 2. ed. São Paulo: Atheneu, p. 81-98, 261280.

Rocha Filho PA 1995. Fitocosméticos. Cosmetic \& Toiletries 7: 18-20.

Santos PRV, Oliveira ACX, Tomassini TCB 1995. Controle microbiológico de produtos fitoterápicos. Rev Farm Bioquím Univ São Paulo. 31: 35-38.

Sharma SB, Nasir A, Prabhu KM, Murthy PS, Dev G 2003. Hypoglycaemic and hypolipidemic effect of ethanolic extract of seeds of Eugenia jambolana in alloxaninduced diabetic rabbits. J Ethnopharmacol 85: 201206.

Timbola AK, Szpoganicz AB, Monache FD, Pizzolatti MG 2002. A new flavonol from leaves of Eugenia jambolana. Fitoterapia 73: 174-176.

United States Pharmacopeia 2003. Ed. Rockville: United States Pharmacopeial Convection, 26, p. 1877-1879, 2380.

World Health Organization 1998. Regional office for the western pacific research guidelines for evaluating the safety and efficacy of herbal medicines. Manila.

Zanoello AM, Mazzanti CM, Gindri JK, Filappi A, Prestes D, Cecim M 2002. Efeito protetor do Syzygium cumini contra Diabetes Mellitus induzido por aloxano em ratos. Acta Farm Bonaerense 21: 31-36.

Zaroni M, Pontarolo R, Abrahão WSM, Fávero MLD, Correa Junior C, Stremel DP 2004. Qualidade microbiológica das plantas medicinais produzidas no Estado do Paraná. Rev Bras Farmacogn 14: 29-39.

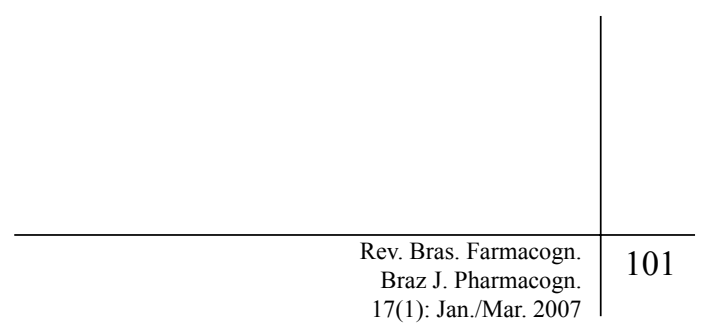

